\title{
Vicuña in Argentina
}

Jeffery Boswall

A footnote to the article on vicuña by $\operatorname{Dr} \mathrm{H}$. Jungius in the last Oryx, May 1972, reported that Jeffery Boswall had seen numbers of vicuña in Argentina, where Dr Jungius feared they were extinct. In this article $\mathbf{M r}$ Boswall describes the sightings made by his party and his reasons for thinking there may still be several hundreds, perhaps more, in Argentina.

In March 1972, seven of us camped for four nights about $10 \mathrm{~km}$ east of Casa Colorada (in the south-east corner of the map), 4320 metres (over 14,000 feet) up in the Sierra Alta. Our purpose was to film vicuñas for $B B C$ television, and the party included Robin J. Prytherch, Douglas Fisher, professional photographer, Donaldo Maciver as interpreter, Jorge Fernandez, archaeologist, Rino Benicio, Don Santos Leano and his son Lino Leano. The filming took most of our energies, but we were able to note down some observations on the vicuñas; in particular we recorded each and every sighting of a herd (unless the same herd was seen again within an hour). The area covered was about 130 sq. $\mathrm{km}$ north and south of our camp; most observations were between 4400 and $4600 \mathrm{~m}$. but two were between 4700 and $4800 \mathrm{~m}$.

Lino Leano, 27 years old, was our key man. His knowledge of both the terrain and the vicuña, coupled with his physical stamina and incredible acuity of sight, rendered our mission much more successful than it would otherwise have been. The observations were mainly his, checked by Donaldo MacIver and/or myself; Robin Prytherch made some independently.

The maximum number of vicuna in view simultaneously was 26 at 09.14 on March 29 th, and 20 at 18.40 on the 27 th. We guessed that about 80 animals were present in the area during the period of our observations, possibly more. We also saw about 20 guanacos Lama guanicoe. The animals were very shy, usually taking flight, if the observer was in view, at distances of one or two kilometres. Two young animals allowed an approach to within 85 metres, and two others, believed to be adult males, to within 200 metres, but these were quite exceptional.

Senor Leano grazes 300 sheep, 40 llamas and 3 donkeys in this area from October to March, but said that they did not feed as high as vicuña would to graze. In winter, when domestic stock are not present, the vicuña graze lower down. He and his father both said that 20 years ago vicunas were much commoner in their area, with family herds of 60 and bachelor herds of 100 . They attribute the decline in numbers to an increase in hunters from outside adding to the pressure of local shooting (Leano had killed about ten vicuñas in the last five years). One hunter was seen on Leano's land during our stay, and stone 'hides' from which the animals can be shot are dotted about the hillsides at strategic points. Shot animals are skinned on the spot and the carcases left. Pelts are sold in Abra Pampa for 50 new pesos, according to Leano, but Ing. 


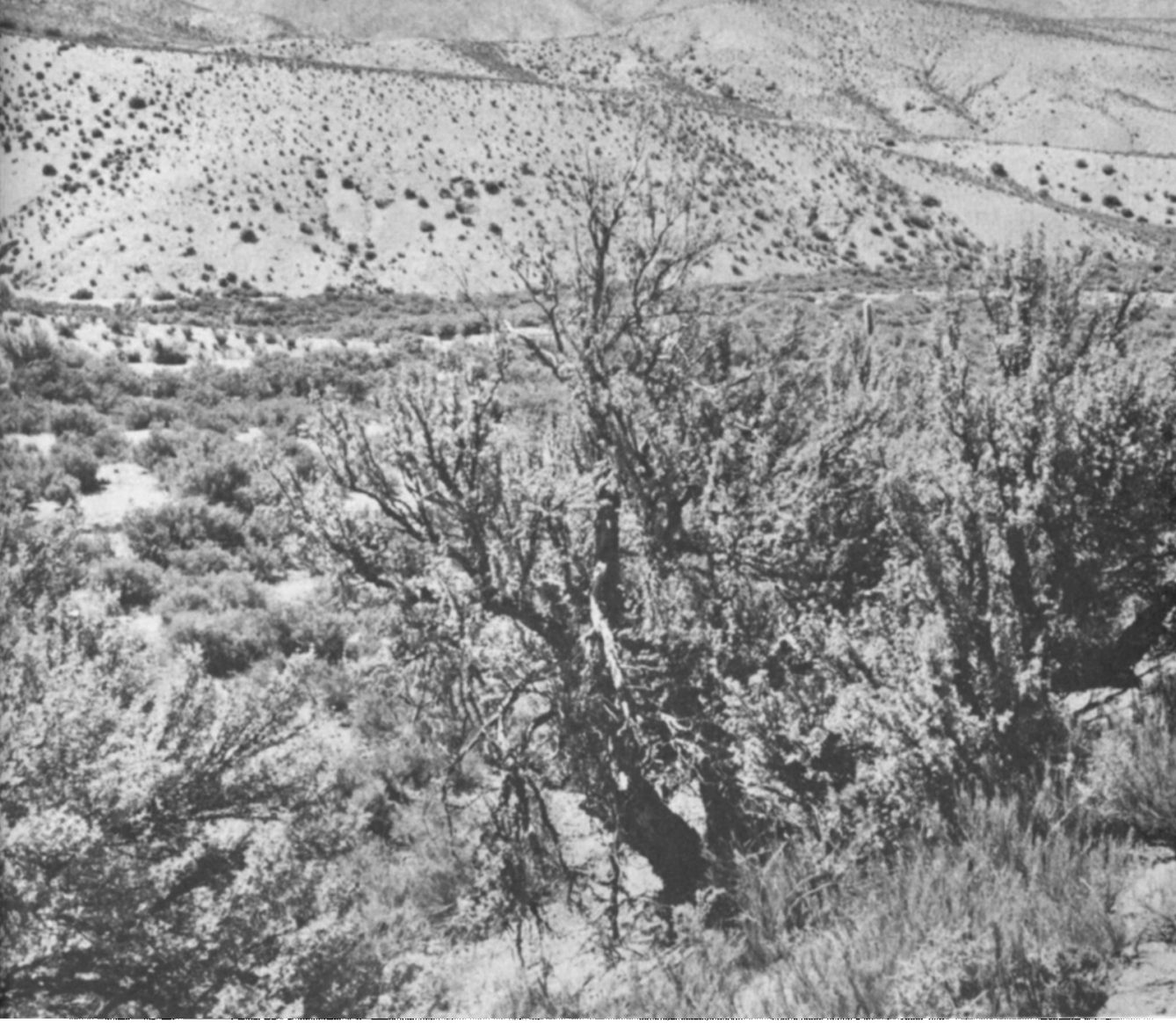

VICUNA HABITAT near EI Aguilar, 14,000 feet up in the central Andes. The trees are the high-altitude quenoa Polylepis tomentella. Douglas Fisher

Ag. Victor Cabezas, head of the INTA* agricultural research station at Miraflores, said that each vicuña yields only 400 grams of wool which fetches only 30 new pesos per kilo. Marrow from the bones of vicuña is said to be good for sciatica and rheumatism, and Leano, on finding a vicuña bone, carefully cracked it open and collected the marrow to sell.

The following list is of other localities in Jujuy province where we saw or had reports of vicunas; all are shown on the sketch map: 
1. In the vicinity of El Portillo, east of Lago de Guayatayoc, about 10 $\mathrm{km} \mathrm{E}$ of Casa Puca (now known as La Poma), groups of 4, 6 and up to 10 vicunas were seen by a reliable informant of $\mathrm{J}$. Fernandez.

2. SW of Coraya, $14 \mathrm{kms}$ W of Humahuaca, where the hills could be considered a northern extension of the Sierra Alta; on March 24 we saw a herd of 9 to 10 .

3. Small scattered herds of up to five vicuñas in the hills $S$ and $W$ of Lago Guayatayoc and Salinas Grandes have been reported in recent years by Señor Carlos Maragoto and Señor Jorge Fernandez, implying a few animals just outside Jujuy province, in Salta.

4. Ing. Ag. Victor Cabezas told me that, despite a serious reduction in numbers, a few still exist $\mathrm{E}$ and $\mathrm{W}$ of Lago Pozuelos, in the north.

5. In March 1972, Dr Alan Sangster saw $2+1$ vicunas, 3 or $4 \mathrm{kms}$ along the road to Lumara, in the north east, from the point where it turns off the main Tres Cruces - Abra Pampa road. Cerro Lumara, 4052 metres, is at the north end of the Sierra del Aguilar.

6. Dr Sangster also saw a herd of about 15 in June or July 1971 in the vicinity of Casabindo, about $50 \mathrm{kms} \mathrm{SW}$ of Abra Pampa.

7. In the Abra Condor area, about $18 \mathrm{kms} \mathrm{NE}$ of Iturbe in the Quebrada de Humahuaca, Jorge Fernandez found vicuñas in 1967 in about the same density as at 'our' Sierra Alta locality. His enquiries in 1972 confirmed that troops of 6,7 and 10 are still frequent today.

8. In the vicinity of Lago de Vilama in the north-west, Fernandez saw herds of up to ten animals in November 1966, but they were much thinner on the ground than in Sierra Alta.

In addition I received one report of vicunas from a locality outside Jujuy province. This was in Catamarca province, further south. Señor Carlos Maragoto, an exploration geologist with experience of vicuña in Jujuy, during a stay of 20 days in November 1970 saw 20-30 animals, and believed there must be more, on the Cerro de la Coipa, north of Laguna de los Aparejos near La Rioja province border (not on this map).

The two areas comprise a very small part of the vicuña's Argentine range in 1957 (Koford 1957), and it seems hardly likely that they are the only ones left; there could well be several hundred, perhaps a thousand. Certainly there are more than Jungius suggested in 1971 when he wrote, 'In Chile and Argentina vicunas are nearly extinct.... we cannot expect more than 100 individuals', and in 1972, 'Probably the vicuña has been exterminated in Argentina'. In Chile, he points out, 200-400 are now known from one locality, at least 200 from another, and not more than 50 from a third.

Ing. Ag. Victor Cabezas, at the INTA station, after reading my report, said he thought that there were about a thousand animals wild in Jujuy province alone, give or take a couple of hundred. Since, as Jungius (1971) has shown, the vicunia is in some ways in competition with domestic stock, it may be of value to have on record Cabezas' very approximate figures for domestic animals in Jujuy province: Llamas Lama glama 50,000; cows 10,000; sheep 600,000; goats 7,500; horses 2,000; mules 500; no alpacas Lama pacos are owned by local people anywhere in Argentina. At the INTA station, 3800 metres up on the Altiplano, they have sheep and pigs, 180 llamas, 40 alpacas, the only ones in Argentina (except possibly in zoos), and the only captive breeding stock of vicuñas. Cabezas brought in about ten wild vicuñas 


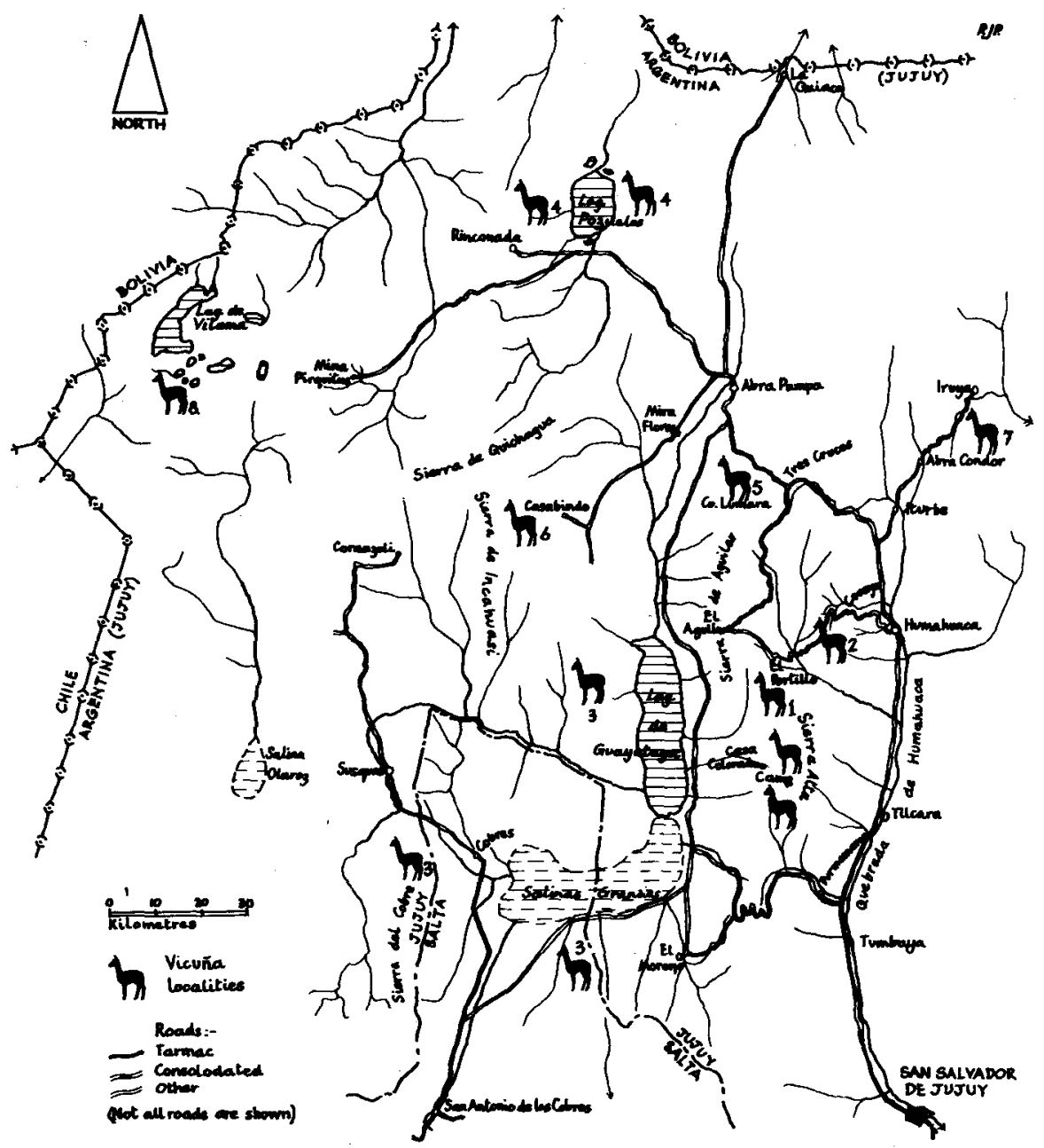

Sites of recent vicuka observations in Jujuy and Salta provinces. The numbers correspond with those in the text opposite. Robin J. Prytherch

when he took over the station 14 years ago; very little new blood has been introduced since then, and today he has 70 animals. I gathered (through an interpreter) that line-breeding of pure vicunas to favour tameness was not' successful; the animals bred, but the offspring remained wild. Great care is taken to keep pure stock pure, but vicuñas have also been crossed with llamas and alpacas in the hope of producing offspring domestically more manageable, and some of these are apparently fertile. These attempts are primarily in the interests of exploiting vicunaa wool, but they are of significance to conservationists.

\section{REFERENCES}

BOSWALL, JEFFERY (1972) Notes on the Status of the Vicuña in Argentina. Report to the Survival Service Commission (unpubl.).

JUNGIUS, H. (1971): The Vicuña in Bolivia. Z. Säugetierkunde 36: 129-146. (1972): Bolivia and the Vicufia. Oryx 11, 5: 335-346.

KOFORD, C.B. (1957): Vicuña and the Puna. EcolMon. 27:7. 


\title{
Sustainable Yield
}

\author{
Harry A. Goodwin
}

In the USSR the saiga antelope population has been built up from under 1000 to one-and-a-half million, which allows the Russians to take an annual harvest of half-a-million animals without affecting the total numbers. This is management of a population on a sustainable yield basis, and this method of conservation through use could be applied to many more wildlife species to save them from declining into extinction. The author of this article, now a Staff Ecologist with IUCN (International Union for Conservation of Nature) in Switzerland, was formerly head of the US Office of Endangered Species.

The term 'wildlife' covers all wild animals that have not been domesticated and are of special interest to man for sport, food, or science, or have aesthetic or ecological values. 'Conservation' of wildlife is the effort or action taken to sustain quality, diversity and a balance in numbers. Because virtually all habitats are influenced by human activities, it is becoming increasingly difficult to maintain the benefits derived from wildlife without management. Conservation and scientific management of wildlife resources are inseparable.

The concept of managing wildlife populations for a sustainable yield is based on the premise that there is a natural wastage or mortality in any healthy population. 'Yield' refers to the individuals taken from a population by fishing, trapping or hunting. 'Sustainable yield' refers to any proportion of the population which, if removed, will be replaced by breeding among surviving individuals, so that the quantity and quality of the population remains constant through successive years of fishing, trapping or hunting.

This harvest can be permitted up to a point of 'maximum sustainable yield' without risking the survival of the population. But if the harvest exceeds the maximum sustainable yield the median life expectancy is lowered rapidly and the population is soon dangerously depleted. All production may then be desperately needed to salvage the population. While a controlled harvest may be allowed from thriving populations, endangered species have to be protected, and depleted species restored to optimum numbers.

The percentage of an unexploited population that will produce the maximum sustainable yield differs among species, as does the percentage of a population that can safely be taken each year. For each population there is an optimum number for production of a maximum sustainable yield, which varies according to management objectives. Generally, only commercial exploitation strives for the maximum sustainable yields of wildlife populations. Wildlife managers normally allow a considerable safety margin.

In wildlife management, research is put to a critical test, and frequent measurements of populations and their habitats, based on a knowledge of population dynamics and habitat requirements, are 


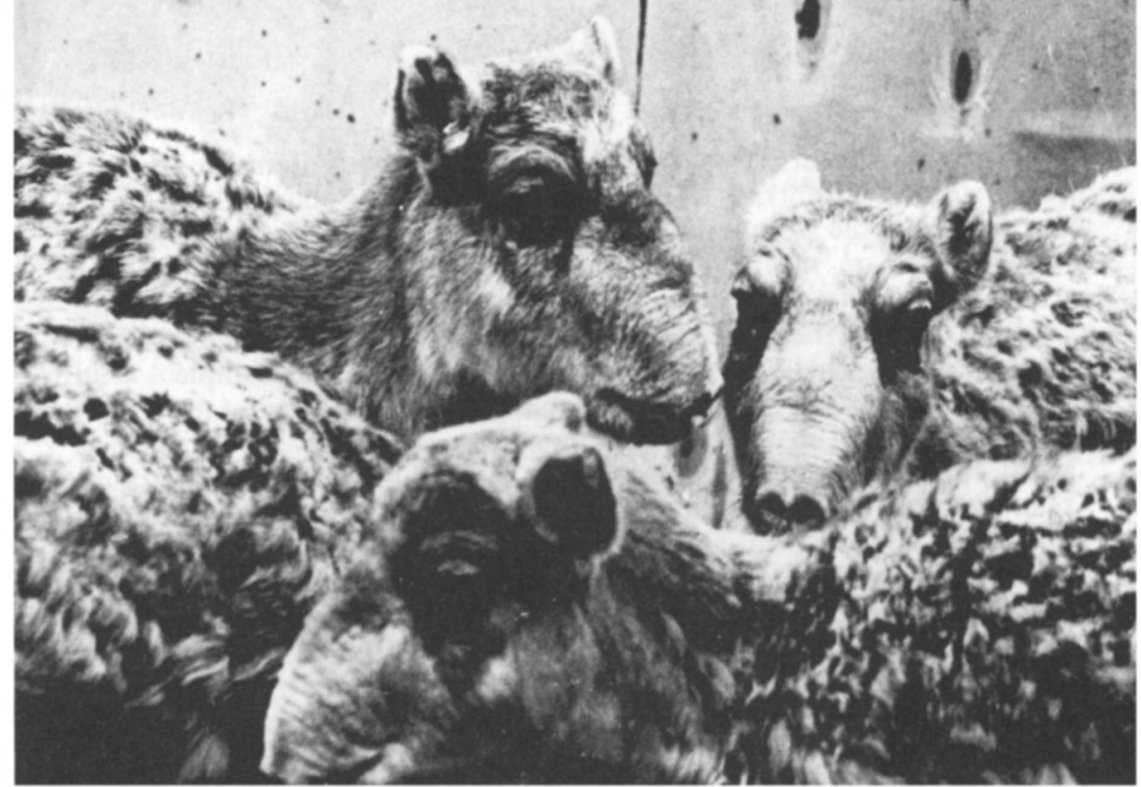

SAIGA ANTELOPES Novosti Press Agency

essential. Collecting the necessary biological data has been relatively easy with species whose habits can be readily observed and where sampling and other research techniques are not difficult to apply, but for others data collection has been slow, and only now, after decades of experience, are we in a position to demonstrate the results of wildlife management for sustainable yield.

The fur seals and sea otters of the North Pacific have been restored from near extinction to an abundance that allows yields of fur worth several million dollars a year. The sable population of the Soviet Union, nearly exhausted shortly after the turn of the century, has been restored through scientific management so that now a sustainable yield of 500,000 pelts a year still allows a steady increase in the population. In 1920 the saiga antelope in the USSR was reduced to fewer than 1000 individuals; today the annual harvest is 500,000 prime animals from herds of 1.5 million.

The restoration of game populations in the United States through protection, habitat management and regulated harvest, provides another outstanding example of wildlife management for a sustainable yield. From fewer than 50,000 elk, scattered in remnant herds in the western states, numbers have been increased fivefold, and now provide a sustainable yield each year that exceeds the total population at its lowest point. More than twice as many pronghorns as existed in 1920 are now taken in a year. Deer were once virtually extinct in most eastern and mid-western states; now there are probably more than 13 million, providing an annual yield of well over two million individuals. During the time in which the herds were being restored, the number taken was consistently held below the maximum sustainable yield to ensure that the harvest was within safe limits.

The use of wild animals as a source of food and products is common to every country. People who live close to nature prefer wildlife to 
other kinds of food; urban societies use it as a luxury item. Hunting, as conducted in countries where game animals are managed, helps to distribute income from industrial areas to rural areas.

There are no means of establishing the total monetary worth of managing wildlife for a sustainable yield. Many of these benefits are qualitative; but there are also quantitative benefits. In some African countries - Uganda, Zambia, Kenya and Rhodesia, for example - wild animals are cropped to supply valuable products and highly nutritious food. It is unfortunate that in many of the countries where protein is sorely needed, lack of management, increasing human populations, reduction of wildlife habitat and over-exploitation are reducing the quantities of game meat and other products. In some areas wild animals are more economic producers of protein than domestic stock grazed on the same range. Trophy hunting, a rapidly increasing business in Africa, Latin America, Australia, New Zealand and several eastern European countries, brings foreign exchange to developing countries; in some it provides the sole source of revenue for wildlife management and protection.

Wildlife management requires regulation and enforcement to control harvest and assure that the yield taken is distributed properly by age and sex. It is also basic that wildlife needs habitats as diverse as the special requirements of different species; each species must have all the components necessary for survival and reproduction.

Nearly all man's activities affect wildlife habitat, which is progressively being removed, reduced or changed. The changes may be major, such as the felling of forest, or the fencing, grazing, or ploughing of savannas; or they may be minor but cumulative, such as impoundments that progressively remove all the floodplain habitat along a river system, change the water temperature, alter the annual regimens of the streams, or bar the migration routes of game animals.

Some species can live in harmony with man; others are intolerant of man and his activities, and management and use must take these realities into consideration. As land use changes, so do the kinds and numbers of wildlife. Such changes have made pests of some species and endangered others.

In some areas, where the presence of wildlife conflicted with man's occupation of the land, entire populations of animals have been exterminated. No balance was sought, no quarter given; the benefits of preserving some wildlife and its essential habitat were not recognized until they were lost, or nearly so. Unfortunately, this same lack of perception prevails today in many developing countries, while the developed ones struggle at great cost both to restore what they once wasted, and to persuade the developing countries not to repeat their mistakes.

Man depends on wildlife for many resources and shares its habitat. He cannot survive unless he manages both wildlife and habitat wisely. Obviously the past abundance of many species cannot be restored; neither can all the existing habitats be entirely preserved, and some of today's species will probably become extinct. But IUCN believes that it will be possible to protect enough habitat to ensure the survival of many species and allow for their use on a sustainable yield basis. 